\title{
Keeping sites in sight: Conversations with teachers about the design of toolkits peculiar to a continuous professional development initiative
}

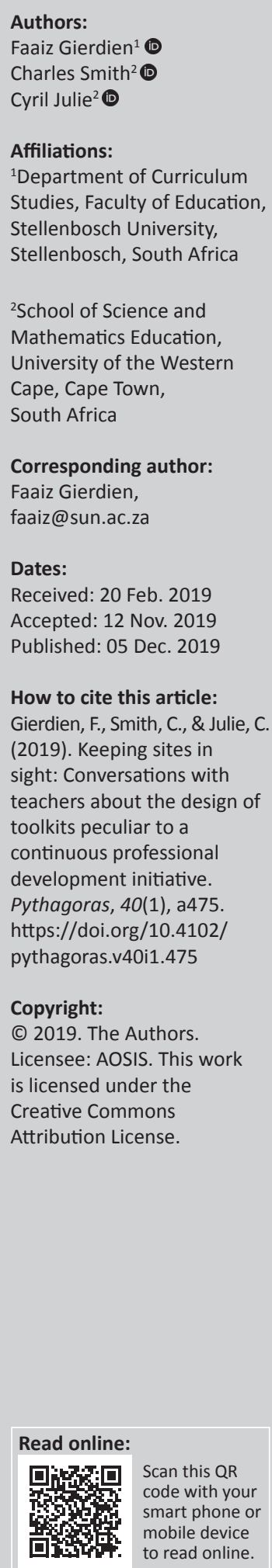

The aim of this article is to shift the notion of 'sites' as places of work peculiar to continuous professional development (CPD) to a theoretical level, independent of, yet intimately connected to, their physical meanings, for example universities and schools. Most CPD initiatives have to contend with at least one of these two sites, in which university-based mathematics educators and school teachers can have different and at times overlapping ways of talking about the same mathematics. Using research on number and operations, non-visually salient rules in algebra and algebraic fractions, and analytic tools and notions peculiar to conversation analysis and ethnomethodology, the authors identify and analyse site-related issues in the design of particular problem sets in Grade 8 and Grade 9 toolkits and related conversations between a mathematics educator and participating teachers. The article concludes with the implications of 'keeping in sight' ways in which universities and schools talk and work when it comes to designing and discussing toolkits.

Keywords: Continual professional development; mathematical toolkits; productive practice; algebraic fractions; visual syntax of algebra; equivalence; conversation analysis; ethnomethodology.

\section{Introduction}

Continuous professional development (CPD) initiatives involve different workplaces, that is, sites. University-based mathematics educators collaborating with in-service teachers designing and using toolkits that have research knowledge inscribed concern the issue of sites, namely the university and the school. Both universities and schools have their peculiar ways of knowing, working and talking or conversing, that is, discursive practices. As a way to begin to understand activities related to $\mathrm{CPD}$, we refer to three physical sites, namely the university (site A), the school or school classroom (site B), and a venue either on or off campus (site C), where the participating teachers and mathematics educators meet and interact. The work of mathematics educators entails contributing to and drawing on mathematics education literature, that is, research knowledge. On the other hand, the schooling system with its associated policy documents (Department of Basic Education [DBE], 2011) provides guidelines and details on the intended and implemented curricula (Julie, 2013), and structure the work of schoolteachers, for example. In this unfolding process of mathematics educators interacting with teachers in the activities of the CPD initiative, mathematics educators and teachers can have differing ways of talking, understanding and working with respect to the teaching and learning of the mathematics. Moreover, at an individual level, mathematics educators and schoolteachers may have site loyalty or preference, meaning that they believe that ways of knowing, talking and working related to their workplaces, for example the university, should be preferred or taken into consideration. During conversations, both groups may invoke non-present others, for example teachers may refer their learners as 'our kids' or 'the child' to make a point when considering certain questions, or mathematics educators may mention 'boundary objects' (Cobb \& McClain, 2006). For example, the Curriculum Assessment Policy Statement (CAPS) policy document has details on cognitive levels for questions, which structure what needs to happen in classrooms. In this article, we examine how a particular CPD initiative designs and uses toolkits as a way to work with teachers. We analyse three data incidents that occurred at site $C$. These involved interactions between the two discursive practices, namely the mathematics educator (i.e. the first author) and a group of teachers where the focus was on examining and conversing about the design of particular Grade 8 and Grade 9 problem sets, which are part of what we call 'toolkits'. The grade level choices had to do with the mathematics educator's involvement in the CPD initiative. The toolkit content served as conversational anchors (Roth, 1998, p. 186) between the teachers and the mathematics educator. The data incidents, presented as data excerpts, are in the form of selected turns of transcribed audiotaped conversation excerpts between the teachers and the mathematics educator. Based on this, we reviewed and 
applied particular conversation analysis tools and ethnomethodology notions, later on, to answer the research question.

The research question that drove this article was: What are the site-related issues when it comes to analysing toolkits-based conversations peculiar to a CPD initiative between mathematics educators and a group of teachers?

Site-related issues stemming from the university or the school were present in the toolkits, as well as in the conversational exchanges associated with them. In all CPD initiatives, university-based mathematics educators, especially, need to be aware of what it takes to get better at 'doing interaction' (Ten Have, 1990, p. 24) when conversing with teachers, in addition to designing toolkits that have inscribed research knowledge related to school mathematics. Answers to this question have implications for CPD initiatives. A review of different strands of literature pertinent to the data incidents, as well as data excerpts, follows.

\section{On sites and the participating teachers}

The teachers involved in the CPD initiative work in high schools or at sites located in socioeconomically challenging environments in the greater Cape Town area. In relation to curriculum reform, some commentators have described teachers working in these schools as 'just too badly educated themselves' (Paton, 2016). Clearly, the teachers are referred to in derogatory ways. To date we know little about what it takes to work with these teachers (Setati, 2005). We do know of pragmatic ways of working of teachers in schools in more affluent environments in relation to curriculum reform in South Africa (Harley \& Wedekind, 2004).

In addition to visiting and interacting with the teachers in their classrooms, the CPD initiative organises workshops and institutes at venues that are on or off campus (site C). Workshops have a time limit of one and a half hours after school and occur four times during the academic year, whereas at institutes, being residential, teachers stay over at a venue and workshops last a day and a half. At site C workshops, mathematics educators and teachers work through and discuss different issues that are of mutual concern. Workshops take the form of a structured programme consisting of a general discussion involving all the teachers, followed by sessions in which teachers from the different participating schools meet and discuss tasks related to their particular grade levels.

Sites are repositories of various kinds of knowledge and have ways of working that are associated with them. For the university-based mathematics educators, knowledge involves competence in the design of scientific investigations that assist in the focused understanding of phenomena. For example, the investigation is into the design of toolkits aimed at engaging with the participating teachers. For the teachers, on the other hand, there is the concern of becoming competent in promoting student learning given complex contextual constraints informed by the 'daily grind' (Lortie, 1975). Differentiating between, say, universities and school classrooms as sites with different offerings is thus a convenient way to present our argument. Site $C$ interactions offer the possibility of mutual engagement, theoretically and practically between mathematics educators and teachers. In other words, site $\mathrm{C}$ is a place or venue where the two groups converse and engage around mathematics content, informed by their respective perspectives related to their workplaces, that is, sites, with toolkits as conversational anchors.

\section{On toolkits and their design}

The toolkits associated with the CPD initiative and the data incidents are versions of curriculum materials (Brown, 2009; Davis \& Krajcik, 2005), professional development tools (Clark-Wilson \& Hoyles, 2019; Collopy, 2003), and supplementary materials that need to 'accompany the various textbooks' that teachers have in their classrooms, that is, in site B (Kindt, 2011, p. 176). They are programmatic in their design, meaning that they relate to the different mathematics in the various grade levels. A toolkit consists of a set of tools - 35 or so problem sets - that span the school mathematics content of a particular grade level, with 'productive practice' as a main design feature. Productive practice aims at enabling learners general ways of working in school mathematics through "“deepening thinking"-like problems whilst practising' (Julie, 2013, p. 93; May \& Julie, 2014; Okitowamba, Julie, \& Mbekwa, 2018; Smith, 2015). Kindt (2011) concludes his discussion of principles of practice with the notion of 'productive practice' (p. 175). In this respect he comes up with several recommendations regarding the design of productive practice problem sets or exercises. Those applicable to the problem sets related to the data excerpts of this study are:

1. Vary the practice formats and activities as much as possible.

2. Challenge the students to reason logically (for example by using coherent strings of problems).

3. Pay attention to verbal readings and writing of algebra rules or formulas. (Kindt, 2011, p. 176)

A component of productive practice relevant to the data incidents of this study is 'deepening mathematical thinking' (DMT) (Watson \& Mason, 1998), which focuses on an engagement with the mathematics. Deepening thinking-like problems have inscribed a design that aims at expanding learners' understanding of mathematical objects as found in the content areas of the intended mathematics curriculum (Julie, 2013), namely the policy documents per grade level (DBE, 2011). Based on this, the problem set questions are phrased in ways where learners are required, for example, to comment on whether mathematical statements are always, never, or sometimes true, and to comment on concepts embedded in procedures for finding the LCM (lowest common multiple) in the case of simplifying an algebraic fraction, to name but a few. We thus view the toolkit design as ecologically relevant in terms of what the teachers have to 


\begin{tabular}{|c|c|}
\hline \multicolumn{2}{|c|}{$\begin{array}{l}\text { Mark with a cross }(\mathrm{X}) \text { the correct block for the given mathematical } \\
\text { statement. } \\
\text { Always true, Sometimes true, Never true. }\end{array}$} \\
\hline $\begin{array}{l}\text { A. If we subtract a number from } 5 \text {, } \\
\text { the answer is less than } 5 \text {. }\end{array}$ & B. If $y^{2}=2 y-3$, then $2 y-2-y^{2}=y^{0}$ is \\
\hline $\begin{array}{l}\text { Always true, sometimes true, } \\
\text { never true. }\end{array}$ & $\begin{array}{l}\text { Always true, sometimes true, } \\
\text { never true. }\end{array}$ \\
\hline $\begin{array}{l}\text { Give reasons with possible examples } \\
\text { for your choice: }\end{array}$ & $\begin{array}{l}\text { Give reasons with possible examples } \\
\text { for your choice: }\end{array}$ \\
\hline
\end{tabular}

FIGURE 1: Problem set A and set B from the Grade 8 toolkit.

teach in their classrooms in terms of cognitive levels; for example, see Figure 1.

\section{A Grade 8 problem set on 'always true, sometimes true, never true'}

The design of problem set A (see left-hand column in Figure 1) requires the learner or teacher to deepen their mathematical thinking or reasoning around the concept of number and the procedure or operation of subtracting a number, which requires interpreting the minus sign. The design exemplifies cognitive level 3, namely 'complex procedures' in the content area of Number, Operations and Relations (DBE, 2011, p. 157), making it ecologically relevant. In the case of the integer -4 ', the minus sign has a unary function: it is a 'structural signifier' (Sfard, 2000). When subtracting a negative integer from 5 , the minus sign has a binary function (Vlassis, 2004, p. 472): there is the procedure or operation of subtraction, which amounts to the difference between 5 and -4 . In this instance, the answer will be greater than 5 . Here the minus sign is an 'operational signifier' (Sfard, 2000): it signifies the procedure or the operation of subtracting, as well as being a negative integer. The DMT is about becoming aware of the minus sign being a structural signifier as well as an operational signifier (Vlassis, 2004), for example $5-(-4)$. For mathematics educators and designers, this always true, sometimes true, never true question is about drawing attention, in a productive way, to the multidimensionality of the minus sign (Vlassis, 2008, p. 560) and integers. Below we elaborate on how this minus sign and its meaning are used in conversations.

In the design of problem set B there is a scramble related to equivalence (Gattegno, 1974), in which it is possible 'to replace one item by another' (p. 83), for example $y^{0}$ can be replaced with 1 (see right-hand column in Figure 1). This problem set requires the learner or teacher to 'unscramble', that is, to replace and to distinguish between 1 and 0 when it comes to the algebraic expressions involving exponent laws, concepts associated with the equality symbol (Kieran, 1981) and meanings of the minus sign. This design stems from teachers' concerns that their learners have difficulty in the content area of Patterns, Functions and Algebra (DBE, 2011, p. 157). It exemplifies cognitive level 3, namely 'complex procedures'. Inscribed in the design are a 'visual syntax of algebra' (Kirshner, 1989), the non-visually salient rule $y^{0}=1$ (Kirshner \& Awtry, 2004, p. 230), and operational and symmetry meanings of the minus sign, when it comes to verbal readings and writing of algebra rules or formulas (see Kindt, 2011, p. 176). 'Visual syntax of algebra' refers to different written out lines of procedures that involve manipulating algebraic expressions, fractions or equations. The non-visually salient rule, as in problem set $B$, is one that is not obvious to the learner. This design in the form of an 'always true, sometimes true, never true' prompt aims at DMT of the learner or teacher with respect to apprehending the syntactic structure of $y^{2}=2 y-3$ and $2 y-2-y^{2}=y^{0}$, that is, the way these two 'elementary algebra' equations 'look' and the connections between them (Kirshner, 1989, p. 274). When checking to see if $y^{2}=2 y-3$, then $2 y-2-y^{2}=y^{0}$ is always, sometimes or never true, there is the procedure: $2 y-2-(2 y-3)$, which is equal to 1 . In this procedure or operation, the second minus sign in front of the brackets, has a 'symmetric role' (Vlassis, 2004, p. 472). When the concept of the distributive property is applied, there is an 'inversion' (p. 472) in the meaning of the minus sign: it becomes a 'plus', as in $2 y-2-2 y+3$, which equals 1 . The teacher or learner thus has to decide on $y^{2}+1-y^{2}$, that is, 1 in relation to $y^{0}$, which is a non-visually salient rule. In other words, there is no obvious route to the solution (DBE, 2011, p. 157).

When speaking with the teachers regarding problem set B, there is the likelihood of 'indexical' expressions or words for 'transposing' and viewing equations or equivalence relationships (Gattegno, 1974) that have symmetric balance (Kieran, 1992). For example, 'bringing it over' is indexical of the procedure of 'transposing' when it comes to checking whether the mathematical statement is always, sometimes or never true. Similarly, in the case of 'you must do the opposite' which, as a procedure, is also a verbal or semantic instance of transposing. We elaborate on these issues below.

\section{A Grade 9 problem set on simplifying an algebraic fraction}

The design in Figure 2 aims at DMT through verbal or semantic readings, and writing of procedures related to syntactic algebra rules for finding the LCM (lowest common multiple) indicated in Lines A to F, when simplifying the algebraic fraction (see Figure 2). This design goes beyond 'simplifying algebraic fractions using factorisation' (DBE, 2011, p. 24), because all the procedures are given in Lines A to F. By way of background, the inclusion of algebraic fractions has historical roots in the incorporation of abstract algebra in the school curriculum (Matz, 1980). Some may view this algebraic fraction in one variable as the 'wrong algebra' because it is not referentially rich (National Council of Teachers of Mathematics [NCTM], 2000). The design should, however, be viewed in light of fostering 'a computational theory of algebraic competence' (Matz, 1980). In this regard, 'write down what was done in the steps numbered A to F' serves as a lexical support system (Kirshner, 1985). As mathematics educators, we view this lexical support system exercise as ecologically relevant because teachers in their classrooms (site C) are familiar with the abstract, base rules (Matz, 1980) of finding the LCM. More interestingly, Lines A 


\begin{tabular}{lll|}
$=\frac{6}{x(3 x-2)}+\frac{5}{3 x-2}-\frac{2}{x^{2}}$ & A \\
$=\frac{6 x}{x^{2}(3 x-2)} \times \frac{x}{x}+\frac{5}{3 x-2} \times \frac{x^{2}}{x^{2}}-\frac{2}{x^{2}} \times \frac{(3 x-2)}{(3 x-2)}$ & B \\
$=\frac{6}{x^{2}(3 x-2)}+\frac{5 x^{2}}{x^{2}(3 x-2)}-\frac{2(3 x-2)}{x^{2}(3 x-2)}$ & C \\
$=\frac{6 x+5 x^{2}-2(3 x-2)}{x^{2}(3 x-2)}$ & D \\
$=\frac{6 x+5 x^{2}-6 x+4}{x^{2}(3 x-2)}$ & E \\
$=\frac{5 x^{2}+4}{x^{2}(3 x-2)}$ & F
\end{tabular}

FIGURE 2: Visually moderated sequences showing procedures for finding the LCM when simplifying an algebraic fraction.

to $\mathrm{F}$ are also instances of visually moderated sequences. Taken from Davis (1984), a visually moderated sequence is 'a visual cue $V_{1}$, which elicits a procedure $P_{1}$ whose execution produces a new visual cue $V_{2}$, which elicits a procedure $P_{2}, \ldots$ and so on' (p. 35). Differently put, the visual cue in Line A elicits the procedure, namely factorises the denominator $x(3 x-2)$, using the concept of the distributive property, which leads to Line B. In Line B, there is an explicit site A input, namely a new visual cue of multiplying by 1 , the identity element for multiplication. In the 'visual syntax of algebra' this becomes $\frac{x}{x}, \frac{x^{2}}{x^{2}}$ and $\frac{(3 x-2)}{(3 x-2)}$. One criticism related to Line $\mathrm{B}$ is that finding the LCM as a set of procedures addresses structural algebra purely as mathematical method (italic in original, Kirshner \& Awtry, 2004, p. 253). However, in Line B, the procedure takes on a 'mathematical' method where the mathematics is in the form of, $\times \frac{x}{x}, \times \frac{x^{2}}{x^{2}}$ and $\times \frac{(3 x-2)}{(3 x-2)}$. Each of the last three is an algebraic or structural equivalence relationship (Liebenberg, Sasman, \& Olivier, 1999) of 1, the identity for multiplication. Another reason for Line B has to do with potentially sustaining learners' epistemic engagement with this syntactic version of the identity for multiplication, as part of procedures for finding the LCM. The latter is a generic 'base rule' (Matz, 1980, p. 95) when it comes to algebraic competence in the domain of algebraic fractions. On its own, Line B is not enough, hence the lexical support system, namely 'write down what was done'. Additionally, in the procedures in Line $\mathrm{D}$ and Line $\mathrm{E}$ there is the symmetric role (Vlassis, 2004) of the second minus sign in the case of the distributive property. When the brackets are removed, this minus sign is an operational signifier related to the operation of subtracting. The minus sign is thus inverted and becomes a 'plus', in other words -2 becomes +4 (see Line E). This last sentence reflects site $C$, that is, a school classroom discourse with respect to the minus sign appearing 'outside the brackets'. The design differs from the usual site $\mathrm{C}$ rules for finding the LCM format, which entails, for example, finding a common denominator.
A way to simplify $\frac{6}{3 x^{2}-2 x}+\frac{5}{3 x-2}-\frac{2}{x^{2}}$ is given in Figure 2 .

Further comments on ways the teachers or mathematics educators refer to $x$ 's as variables and 'terms' in Figure 2 are necessary. In all the lines, the $x$ 's have 'symbolic value' (Matz, 1980, p. 131) that is suspended from arithmetic, meaning that there is no need to substitute numerical values for the $x$ 's. If the algebraic fraction or expression were to represent a rational function, then the $x^{\prime} \mathrm{s}$ as variables can take on the particular real number values, excluding 0 and $\frac{2}{3}$ (see Line

A). However, when commenting on the steps in simplifying this algebraic fraction, learners or the teachers in this case have to 'relax arithmetic expectations' (p. 131) involving well-formed answers, that is, instances where the answer is a number. All the operations involving the $x^{\prime}$ s are thus 'suspended operations' (Matz, 1980, p. 131). In fact, Lines A to F deal with the 'surface structure' (Kieran, 1992) of the factorised 'terms' in the denominators shown in Lines A to F. The $x$ 's are thus not 'variables' that take on numerical values. In the mathematics curriculum, variables have many uses and different meanings (Rosnick, 1981; Usiskin, 1988), which we will not go into here. This can be ambiguous to site C classroom teachers - because there are instances in the mathematics curriculum where the $x^{\prime}$ s do take on numerical values, that is, they become variables. For an interesting discussion on the role and power of ambiguity in mathematics as a discipline, see Byers (2007, p. 78).

\section{On applying conversation analysis and ethnomethodology}

Conversation analysis is a research tradition that focuses on the order, organisation and orderliness of social action, particularly those social actions that are located in everyday interaction, in discursive practices, and in the sayings, tellings and doings of members of society (Psathas, 1995, p. 2). Teachers and mathematics educators, as members of society, have their respective discursive practices, that is, peculiar ways of knowing, talking and working. Conversation analysis has elaborate and detailed notations for voice inflections, emphases and pauses, and so forth, when it comes to doing line-by-line transcriptions of audiotaped conversations, which we will not focus on. Instead, we refer to conversation analysis and use its analytic tools in an 'applied' sense because these offer 'bottom up' value when it comes to identifying site-related issues in the data excerpts (see below). In particular, conversation analysis is concerned with 'meaningful human conduct across settings and modalities (visual, auditory) of production and understanding' (Pomerantz \& Fehr, 2011, p. 166), which are core features of all CPD initiatives. Historically, conversation analysis and ethnomethodology are connected in their 'broad contours' (Maynard \& Clayman, 2003, p. 176), with the latter preceding the former (Heritage, 1984, 2009; Lynch, 2000; Maynard \& Clayman, 2003; Ten Have, 1990). Ethnomethodology is about the study of methods, which can be spoken or written, that people or participants within a given linguistic community (ethno) use to establish and 
maintain intersubjective understanding based on their 'practical sociological action and reasoning' (Garfinkel, 1967, p. 1). The data excerpts reflect many instances where the teachers and the mathematics educator talk or reason, that is, where they share their practical understandings and methods, peculiar to their places of work, in relation to the design of the problem sets.

In an applied sense, the conversation analysis analytic tools, namely turn transition relevance place (TTRP) (Lynch, 2000, p. 530), and repairs and epistemic order (Heritage, 2009, pp. 305-309; Pomerantz \& Fehr, 2011; Ten Have, 1999, pp. 111-121), in addition to the EM notion of indexicality, are useful in terms of answering the research question. A recent study highlights the analytic value of applying 'ethnomethodological approaches', which include the mentioned analytic tools in the case of the mathematics classroom, that is, site B interactions (Ingram, 2018). In the line-by-line transcriptions of conversation excerpts, a turn viewed as a TTRP (Lynch, 2000, p. 530) can be used to identify and to analyse understanding between the teachers and the mathematics educator. In any ongoing conversation sequence, a turn is thus a transition 'place' where participants are trying to understand one another, through dialogue. This 'place' comes about dialogically and is dependent upon the exhibited understandings between the teachers and the mathematics educator, for example. A TTRP as an analytic object in a conversation sequence is essentially 'local and situated' (Lynch, 2000, p. 530), meaning that it depends on how recipients respond, and how the current speaker reacts to the recipients' utterances to the current turn as it unfolds. The various turns in the data excerpts are thus 'places' that reveal ways of talking and knowing peculiar to a site, which could be site $\mathrm{A}$, the university, or site $\mathrm{B}$, a school classroom. In this sense, site-related issues can be identified in the utterances of the mathematics educator or the teachers, whether they meet at a university, a school or elsewhere. Repairs are 'places' in the conversation where either the mathematics educator or the teachers fix, modify or correct what they are saying (Pomerantz \& Fehrer, 2011, p. 171). Related to 'repairs', epistemic order (Heritage, 2009) refers to 'places' in the conversation where either the mathematics educator or the teachers position or orient themselves relative to the mathematics inscribed in the design of the problem sets, based on their respective discursive practices.

Indexicality, in ethnomethodology parlance, refers to expressions or words whose sense cannot be determined without knowledge of the purposes of the user or the context of use. What the teachers and the mathematics educator say, as transcribed in the data excerpts, are reflexively related to the context, namely a CPD workshop (site C) meeting. This means that interactions between the mathematics educator (i.e. the first author) and the teachers have to be analysed in terms of a site $\mathrm{C}$ context at quite a local level of interaction, for example what occurs before and after the interaction, or 'before and after an individual turn within an interaction' (Ingram, 2018). In a seminal discussion on indexicality,
Barnes and Law (1976, p. 228) conclude that it is an essential and irreparable feature of all talk, scientific or otherwise. This includes ambiguity in the ways mathematics educators, mathematicians (Byers, 2007) and teachers talk in general and about the same mathematics. Byers notes the power of ambiguity and ambiguity in mathematics as a discipline. A mathematics educator and a teacher, for example, may use 'minus' and 'subtract' interchangeably. The phenomenon of indexical expressions or words is truly unavoidable (Garfinkel, 1967). Although indexical expressions or words (indexicals) 'are of enormous utility, they are awkward for formal discourse' (p. 5). A teacher may speak of 'any number' and not necessarily use 'objective expressions' (Garfinkel, 1967 , p. 5), for example real numbers or negative integers (see Figure 1). Teachers may not use 'transpose', but say 'you bring it over', a procedure related to solving an algebraic equation. In the case of the symmetry of an equation, they may say 'minus $y$ squared on that side and on this side' and not use more objective expressions like 'perform the same operation on both sides of the equality sign' when dealing with equivalence (Gattegno, 1974). Another example is that of mathematics educators who view 1 - the identity for multiplication - as having a numerical equivalence as well as an algebraic or structural equivalence (see Figure 2). Teachers, on the other hand, do not speak in such formal ways about 'the same mathematics'. The meaning and understandability of any indexical expression or word, rather than being fixed by some abstract definition, depend upon the environment in which it appears (Maynard \& Clayman, 2003, p. 183), for example a school or university. Ethnomethodologists do not treat indexical expressions or words as a nuisance to be remedied (Maynard \& Clayman, 2003, p. 183). Instead they view them as 'resources' for more objective expressions or words (Ingram, 2018).

\section{Research framework}

To answer the research question we need a research framework (Niss, 2007) shown in Figure 3. Its rows and columns serve as a way to integrate the different strands of literature. In the top row (level 1) there is a general description of the empirical data incidents. Level 2 and Level 3 are the analytic levels, which contain incomplete details on the conversation analysis and ethnomethodology analytic tools and notions and the literature related to Grade 8 and Grade 9 problem sets.

\section{Methods of data analysis}

The unit of analysis, 'site-related issues', has two interconnected data sources (see Level 2 and Level 3 in Figure 3). The first is in the design, that is, the wording of the particular Grade 8 or Grade 9 problem sets (see Figure 2 and Figure 1). The second is selected turns of transcriptions of conversation excerpts peculiar to the problem sets which served as the conversational anchors. In the case of the latter, we applied - in a selective way - the interchangeable conversation analysis and ethnomethodology tools and notions, namely turn transition relevance place (TTRP) or 


\begin{tabular}{|l|l|l|}
\hline Descriptive/ & Level 1 & $\begin{array}{l}\text { Mathematics educator converses with } \\
\text { teachers at site B with particular problem } \\
\text { sets from Grade 8 and Grade 9 toolkits as } \\
\text { conversational anchors. These } \\
\text { conversations are audiotaped and } \\
\text { transcribed. }\end{array}$ \\
\hline Level 2 & $\begin{array}{l}\text { Teachers see and discuss the design of } \\
\text { particular Grade 8 and Grade 9 problem } \\
\text { sets of the toolkits. } \\
\text { Problem sets in the two toolkits: } \\
\text { See Figure 1 and Figure 2. } \\
\text { - Grade 8 } \\
\text { - Grade 9 }\end{array}$ \\
\cline { 2 - 4 } & $\begin{array}{l}\text { Applying analytically distinguishable but } \\
\text { interlocking conversation analysis tools of } \\
\text { turn-transition relevance place, repairs and } \\
\text { epistemic order to the turns of transcription } \\
\text { of conversation excerpts helped in } \\
\text { identifying evidence of site-related issues. } \\
\text { In this respect, applying ethnomethodology } \\
\text { notions of indexical expressions or words } \\
\text { served a similar purpose. }\end{array}$ \\
\hline Level
\end{tabular}

FIGURE 3: Skeletal outline of the research framework.

turn, repairs, epistemic order and indexicals (indexical expressions or words). This enabled us to identify and to analyse the unit of analysis and thus how and where deeper mathematical thinking occurred or not. As stated earlier, a TTRP can signal a repair or an epistemic order, and can exemplify indexical words or expressions used either by the mathematics educator or the teachers. By examining the TTRP or turns, it became possible to find 'places' in the transcriptions where the teachers and the mathematics educator talked about or commented on site A inputs inscribed in the design of each of the three problem sets. Evidence of 'keeping sites in sight' are thus the turns or repairs in the conversation excerpts where the mathematics educator attempts to DMT in relation to the design of the problem sets based on teacher responses. To follow the analysis, the reader has to view the relevant problem sets above together with the numbered turns of the transcriptions of conversation excerpts. In the presented excerpts below, ME stands for mathematics educator and T1, T2, T3, .. for the different teachers. We analysed the three problem sets and associated conversation excerpts separately.

\section{Ethical considerations}

The research ethics committee of the university of which this particular study is a part cleared the project (registration number 11/9/33). The project was also approved by the Western Cape Education Department through a Memorandum of Understanding between the university and the Western Cape Education Department.

\section{Site-related issues}

\section{Grade 8: Problem set A}

The 29 turns of transcriptions (see Table 1) were selected because they contain evidence of the following interconnected site-related issues: indexical expressions and words related to signs as they appear in (1) number and (2) operations. We divided the transcriptions into turns, each of which reveal different 'places' where the mathematics educator tries to 'keep sites in sight'. Site A evidence is in the design of the problem set and in ways the mathematics educator talks to the teachers in the conversation excerpts. On the other hand, site $\mathrm{B}$ evidence is in ways the teachers speak about and understand the design or wording of the problem set.

In Table 1 the mathematics educator orients the two teachers (T1 and T2) to the design of the problem set. In Turn 3, the teacher (T1) mentions 'add and subtract'. This is indexical because 'add and subtract' can only refer to 'numbers'. Turn 4 is a repair in which the mathematics educator aims to have the teacher modify or correct, that is, deepen her mathematical thinking in relation to an answer to 'if we subtract a number from 5, the answer is less than 5', being 'always, sometimes or never true'. Turn 4 and Turn 6 are repairs on the part of the mathematics educator, which also reflect an epistemic order with respect to number and the minus sign (Turn 6).

'Signs' are indexical because they could refer to positive or minus signs as operational or structural signifiers. In Turns 9-11 in particular, the teacher (T1) refers in an indexical way to two meanings of the minus sign. For example, in the case of 'subtract', the minus sign is an operational signifier, implying the binary operation of subtraction. 'A negative' and 'a negative number', on the other hand, can refer to a negative integer or a real number, in which case the minus sign is a structural signifier, assuming a unary operator meaning, for example 4. Turn 10 and Turn 12 are further repairs and an epistemic order in which the mathematics educator aims at DMT with respect to the 'site A' designer intentions, namely always, sometimes or never true. DMT happens in Turn 13 where the teacher uses 'minus' to mean the binary operation of subtraction (' 5 minus negative 4 '). In Turn 13 the teacher (T1) moves from the indexical ' $a$ number' to making a formal distinction by specifying a negative integer. In this turn 'minus', that is, the minus sign, is an operational signifier. Turn 14 is the repair in which T2 corrects, that is, fixes, an earlier response as in Turn 11.

In Turns 15-22, Turn 17 can be viewed as a TTRP in which the mathematics educator directs the teachers' attention to the site $C$ boundary object - the CAPS policy document - and its relevant cognitive level 3 details, namely 'complex procedures'. This is an instance of 'keeping sites in sight', in which the mathematics educator brings into view how and where the site A-designed problem set focusing on the two meanings of the minus sign connects with 'complex procedures'. Turn 20 reveals further instances of repairs in which the teacher modifies his or her thinking on number and the meanings of the minus sign as being either an operational or a structural signifier. The teacher uses 'minus' and 'negative' interchangeably. For example, Turn 20 ('it can be minus 5'), ('it can be a negative number'), and ('negative $\left.4^{\prime}\right)$ in which the minus sign has a structural meaning. In turn 20 'minus' also has an operational meaning ('5 minus negative 4 ').

In Turn 20 to Turn 29, there are thus further instances of epistemic order, in the form of repairs with respect to number and the 
TABLE 1: Transcript related to Grade 8: Problem set A

\begin{tabular}{|c|c|c|}
\hline Turn & Speaker & Utterance \\
\hline 1 & ME & $\begin{array}{l}\text { This is that new stuff where you have a mathematical statement and you have 'always, sometimes and never true'. The idea is to jolt you. If you look at the example. If } \\
\text { you subtract a number from } 5 \text {, is that answer always less than } 5 \text { ? Is that 'always true, sometimes true, or never true'? What do you think this is pitching at? } \\
\text { [Silence] }\end{array}$ \\
\hline 2 & ME & If you look at ... \\
\hline 3 & $\mathrm{~T} 1$ & ... to see if the learner can subtract and add. \\
\hline 4 & ME & Yes ... but, if you subtract a number from 5 , is the number always less than 5 ? Is that 'always true'? \\
\hline 5 & $\mathrm{~T} 1$ & No, 'sometimes true'. \\
\hline 6 & ME & When is it 'sometimes true'? When is it 'never true'? That kind of thing. Do you want to say a little bit more? \\
\hline 7 & $\mathrm{~T} 1$ & It depends on the signs. \\
\hline 8 & ME & By signs, you mean? \\
\hline 9 & $\mathrm{~T} 1$ & They can subtract a negative from 5 . They are going to subtract a negative number from 5 , then it will obviously give you more than 5 . \\
\hline 10 & ME & More than 5 or less than $5 ?$ \\
\hline 11 & $\mathrm{~T} 2$ & Yes, it's 'always true' ... for me it's 'always true'. \\
\hline 12 & ME & Always true? \\
\hline 14 & $\mathrm{~T} 2$ & Oh, okay ... it can be 'sometimes true', if I think about it now. It makes the learner think. When you asked what this thing ... \\
\hline 15 & ME & Yes. \\
\hline 16 & $\mathrm{~T} 2$ & ...is pitching at, are you asking us in terms of what level of thinking or ... what are you asking us? \\
\hline 17 & ME & What do you think? Because if I look at the cognitive levels in CAPS, you have complex procedures, right? Level 3. \\
\hline 18 & $\mathrm{~T} 2$ & Right. \\
\hline 19 & ME & So I'm actually pitching it at that level, because ... \\
\hline \multirow[t]{2}{*}{20} & $\mathrm{~T} 1$ & $\begin{array}{l}\text {... it makes the learner think. If I think now, my first answer was wrong and I had to rethink and I had to read }{ }^{1} \text { it again, read it again, because it said, 'Subtract a } \\
\text { number from 5.' You didn't say, 'Subtract zero or } 20 \text { or } 10 \text { ', so it can be any number: it can be minus 5, it can be } 20 \text {, it can be a } 100 \text {. So when I read it the second } \\
\text { time, then I said, 'Sometimes true.' }\end{array}$ \\
\hline & & $\begin{array}{l}\text { We leave that option that it can be a negative number or a positive number. We're forcing the child to think. You forced me to think. I had to read it the second } \\
\text { time ... if that's the right answer there. }\end{array}$ \\
\hline 21 & $\mathrm{~T} 1$ & Okay to me, when I ... to me here, the reading ... reading, you need to read, first of all ... \\
\hline 22 & ME & Right. \\
\hline 23 & $\mathrm{~T} 1$ & $\begin{array}{l}\text { And then, after you read, you then need to think because, most of all, if you don't read this question right, you will get it wrong. So yes, it's testing, it's pitched } \\
\text { at the learners' reading skills. }\end{array}$ \\
\hline 24 & $\mathrm{~T} 2$ & ... But it's not a specific question. \\
\hline 27 & $\mathrm{~T} 1$ & $\begin{array}{l}\text { Yes, it is productive ... because, say, for instance, you are in a group, then the one will say, like, now the one will say 'always', then I say now 'sometimes true' ... } \\
\text { and then you will discuss it and the other one will come to the realisation that there are more answers. }\end{array}$ \\
\hline 28 & $\mathrm{~T} 2$ & Ja. \\
\hline 29 & $\mathrm{~T} 1$ & $\begin{array}{l}\text { And especially here where you say, 'Give reasons'. For this question, it is good because now you're saying it's 'always'. Now show me, give me a reason why you } \\
\text { say ... if that weren't there, then it would have been semi-productive ... but, with that being there, it is actually productive. }\end{array}$ \\
\hline
\end{tabular}

${ }^{1}$ Italics are used to indicate emphasis on the part of the speaker.

minus sign. Turn 20 reveals evidence of $\mathrm{T} 1$ clarifying the indexicality of 'any' number by giving the examples of positive and negative integers. In this turn T1 becomes more aware of two meanings of the minus sign, which this respondent did not consider before (see Turn 14). T1 does not mention negative integers or real numbers explicitly, meaning that a resulting siterelated issue is to use current indexical articulations as a 'resource' for a more formal discourse on meanings of the minus sign and responses to the particular DMT question.

In summary, 'keeping sites in sight' from the analysis above is about the mathematics educator becoming aware of the indexical expressions and words in the conversation exchanges at the level of the turns and repairs, in addition to aligning the productive practice or DMT inscribed design in the problem set with the site C CAPS policy document guidelines on cognitive levels.

\section{Grade 8: Problem set B}

Problem set B requires the learner or teacher to unscramble distinguish between 1 and 0 when it comes to the equivalence relationships involving exponent laws - concepts associated with the equality symbol and meanings of minus and the minus sign (see Table 2). The selected 28 turns of transcribed conversation excerpts contain evidence of the following three interconnected site-related issues: indexical expressions and words with respect to (1) the non-visual salience of $y^{0}=1,(2)$ transposing and performing the same operations on both sides of the equality sign as instances of equivalence and (3) meanings of the minus sign as it appears in (1) and (2).

In Turns $1-12$, the two teachers begin to unscramble the problem set with its key focus on the non-visual salience of $y^{0}=1$. Based on preceding conversation details not given, Turn 1 is a repair, in which the mathematics educator asks the teachers, in words, if $y^{2}-y^{2}=y^{0}$ In this turn, minus is used as an operational signifier, that is, it has to do with the operation of subtraction. As is evident from Turn 2 and Turn 3, the teachers understand the question. 'Minus' is an indexical word. A more objective word corresponding to the meaning of 'minus' that could have been used is 'subtract'. The point to note is the indexicality around the use of 'minus', based on seeing the minus sign in the design of the problem set. This 
TABLE 2: Transcript related to Grade 8: Problem set B.

\begin{tabular}{|c|c|c|}
\hline Turn & Speaker & Utterance \\
\hline 1 & ME & Is $y$ squared minus $y$ squared equal to $y$ to the power of zero that is what it is pitching at. \\
\hline 2 & $\mathrm{~T} 2$ & No. \\
\hline 3 & $\mathrm{~T} 1$ & No. \\
\hline 4 & T1 & I think, for our kids, this is a bit too ... \\
\hline 5 & $\mathrm{~T} 2$ & If you subtract anything from itself, it gives you zero, doesn't it? \\
\hline 6 & ME & Right. So they have a zero there. \\
\hline 7 & $\mathrm{~T} 2$ & Yes, but they ... \\
\hline 8 & T1 & Because $y$ to the power zero is $1, y$ to the power of zero is 1. \\
\hline 9 & $\mathrm{ME}$ & Right ... so? \\
\hline 10 & $\mathrm{~T} 2$ & So here are the equations they working with, here they are working with exponents. \\
\hline 11 & $\mathrm{~T} 1$ & Exponents. \\
\hline 12 & $\mathrm{~T} 2$ & They must know their laws. \\
\hline 13 & $\mathrm{ME}$ & $\begin{array}{l}\text { I agree...so? } \\
\text { [Silence] } \\
\text { Is that 'never true, some true'? }\end{array}$ \\
\hline 14 & $\mathrm{~T} 1$ & $\begin{array}{l}\text { If you take } y \text { to the power zero, if you bring it over, then it is minus one because it is one on that side, } y \text { to the power zero is one. If you bring it over, then it is } \\
\text { negative one. Are you with me? So minus } 1 \text { minus } 2 \text { gives you minus } 3 \text {. } \\
\text { [Silence] }\end{array}$ \\
\hline 15 & $\mathrm{~T} 2$ & $A h \ldots$ \\
\hline 16 & $\mathrm{~T} 1$ & $\begin{array}{l}\text { Can you see it? So minus } 1 \text { minus } 2 \text { gives you minus } 3 \text {. Then you have there two } y \text { minus } 3[(2 y-3)] \text {. If you take minus } y \text { squared }\left[-y^{2}\right] \text { over it becomes } y \\
\text { squared }\left(y^{2}\right) \text {. So then, you have those formulas being the same. To me that is just the same formula being scrambled. So that is the same formula, the same } \\
\text { equation, or whatever. }\end{array}$ \\
\hline 17 & ME & So 'always true, sometimes true'? \\
\hline 18 & $\mathrm{~T} 1$ & 'Always true', to me. \\
\hline 19 & $\mathrm{~T} 2$ & But if you look at it, then the children will say it can't be true. You teach them to get rid of a thing on the one side, you must do the opposite. \\
\hline 20 & ME & You must do the opposite ... meaning what? \\
\hline 21 & $\mathrm{~T} 2$ & You're going to minus $y$ squared on that side and on this side. \\
\hline 22 & ME & Okay, so now you get an idea of the 'always, sometimes, never' story. It's pitched at definitely at level 2 upwards. \\
\hline 23 & $\mathrm{~T} 1$ & Yes, definitely. \\
\hline 24 & $\mathrm{~T} 2$ & Definitely 2 upwards. \\
\hline
\end{tabular}

repair is aimed at having the teachers modify, that is, deepen their mathematical thinking with respect to the zero, which in this case is an exponent (see Turn 6), by contrasting it with subtracting two equivalent algebraic terms, for example $y^{2}$, which also gives 0 , which both teachers answer correctly. Turns 8, 10 and 11 are evidence of the teachers becoming aware of how the inscribed design of the problem set scrambled equations and exponents.

Of interest in Turns 13-24 are the indexical expressions and words the teachers use in arriving at the correct answer, prompted by the repair in Turn 20 (see also Turn 21), namely that the mathematical statement in the problem set is always true. Turn 13 is a repair in which the mathematics educator 'keeps in sight' the design of the problem set by having the teachers modify, that is, deepen, their mathematical thinking. In the case of 'you take it over,' 'you bring it over' 'take over,' and 'to get rid of a thing on the one side, you must do the opposite' (Turns 14, 17 and 22), the more objective word is 'transpose'. In Turn 14 the use of 'minus' has both an operational meaning the operation of subtraction - and a structural meaning as in 'minus $y$ squared'. In this turn the teacher also uses 'minus' and 'negative' interchangeably. In one instance, T1 means the integer -1 and, in another instance, the operation of subtraction. In Turn 1 the mathematics educator does the same, that is, uses 'minus' instead of the more objective 'subtract'. This also happens in Turn 21. The indexical words and expressions, 'you're going to minus on that side and on this side' (Turn 21), are evidence of the symmetry of an equation. More objective words are 'you're going to perform or do the same subtraction operation on both sides of the equality sign'. In the case of 'the same formula, the same equation or whatever' (Turn 16), the more objective expressions and words are 'equivalent expressions on either side of the equality sign, that is, an identity or, more comprehensively, an instance of equivalence (Gattegno, 1974, p. 83).

In Turns 22-26, the mathematics educator 'keeps sites in sight' by pointing out how the design of the problem set connects with the cognitive level on 'complex procedures' specified in the CAPS document. Teacher (T1) reiterates how and where the non-visually salient rule $\left(y^{0}=1\right)$ is inscribed in the design of the problem set, which T2 points out in Turn 26.

\section{Grade 9: Simplifying an algebraic fraction}

We selected 21 turns of transcriptions of conversation excerpts (see Table 3) because they reveal evidence of the following site-related issues: (1) indexicality around 1 as the identity element for multiplication, (2) the meaning of variable and (3) how finding the LCM (lowest common 
TABLE 3: Transcript related to Grade 9 algebraic fractions problem set.

\begin{tabular}{|c|c|c|}
\hline Turn & Speaker & Utterance \\
\hline \multirow[t]{2}{*}{1} & $\mathrm{ME}$ & What do you think was done in Line $B$ ? \\
\hline & & [Silence] \\
\hline 2 & $\mathrm{ME}$ & When you see that $x$ over $x$, what do you think is happening there? \\
\hline 3 & $\mathrm{~T} 1$ & Multiply. \\
\hline 4 & ME & $x$ over $x$ \\
\hline 5 & $\mathrm{~T} 1$ & It's the same almost like multiplying with one. \\
\hline 6 & ME & Why do you say that? \\
\hline 7 & $\mathrm{~T} 1$ & $x$ over $x$ is one, so they're not changing anything. \\
\hline 8 & $\mathrm{~T} 2$ & That is actually the KGV. [Afrikaans for LCM] \\
\hline 9 & T3 & The one over one will not change. \\
\hline 10 & $\mathrm{~T} 2$ & The $x$ is a variable. \\
\hline \multirow[t]{2}{*}{11} & $\mathrm{~T} 4$ & But why is it that they choose the $x$ ? \\
\hline & & Kan ek dit in Afrikaans sê? [May I say it in Afrikaans?] \\
\hline 12 & ME & Yes, say it. Okay I will translate. Go ahead. \\
\hline 13 & T4 & $\begin{array}{l}\text { Kyk, hulle het nou hier } x \text { oor } x \text { en dan is daar die } 3 x \text { minus } 2 \text { [Look they have } x \text { over } x \text { here, then there is } 3 x \text { minus } 2 \text { ]. Right? So to make a common } \\
\text { denominator, you have to multiply the first term with the } x \text {, and to have that same term at the bottom [pointing to the }\left(\frac{5}{3 x-2}\right) \text { ] you have to multiply with } \\
x \text { squared }\left[x^{2}\right] \text {, to get the same ... I don't know how to explain that. Can I go on? } \\
\text { [T4 is looking at and referring to the visually moderated sequence as in Figure 2.] } \\
\text { Multiply with } 3 x \text { minus } 2 \text {. }\end{array}$ \\
\hline 14 & ME & Yes, go on. \\
\hline \multirow[t]{2}{*}{15} & T4 & $\begin{array}{l}\text { And then you minus the } 2 \text { [pointing to }-\frac{2}{x} ; \text { See Line } C \text { ], and the last term, but you have to multiply that term with three } x \text { minus two [3x-2], to get all of } \\
\text { them on the same denominator. }\end{array}$ \\
\hline & & And that step over there is to make all the terms have the same ... \\
\hline 16 & $\mathrm{~T} 1$ & Denominator. \\
\hline 17 & T4 & The same denominators, the same. \\
\hline 18 & ME & Equivalent ... is that what you want to say? \\
\hline 19 & T4 & Yes. \\
\hline 20 & $\mathrm{ME}$ & $\begin{array}{l}\text { Right. So, in other words, this idea of multiplying by one, that is how you convert ... If I were to use this example, you convert } \frac{1}{3} \text { to } \frac{2}{6} \text { by simply } \\
\text { multiplying it by } 2 \text { over } 2 \text {, or } 3 \text { over } 3 \text { by multiplying it by one, but you rewrite one as } 3 \text { over } 3 \text {. So here it is } x \text { over } x, x \text { squared over } x \text { squared and } 3 x \text { minus } \\
2 \text { over } 3 x \text { minus } 2 \text {. And then, if you look at Line C, then that's the game, to get the LCM. Then you have the LCM. Then it is a matter of taking care of the } \\
\text { so-called numerators, which become } 6 x, 5 x \text { squared and two bracket } 3 x \text { minus } 2\left[6 x, 5 x^{2} \text { and } 2(3 x-2)\right] \text {. }\end{array}$ \\
\hline 21 & T3 & If you can explain why you did this in Line B. Like I can explain to learners, then I don't see any problem. They'll be able to do C, D, E and F. \\
\hline
\end{tabular}

multiple) when simplifying the algebraic fraction relates to (1) and (2).

In the beginning the teachers together with the mathematics educator orient themselves to the design of the problem set. Central to this design is a lexical support system for finding the LCM (see Grade 9 problem set), which is evident from reading what the teachers say in all the different turns. Turn 1, in the form of a question, is an epistemic order that aims at DMT with respect to numerical and algebraic equivalences in the case of 1 as the identity for multiplication. In Turn 4, the mathematics educator's response, there are indexical expressions that correspond to the more formal 'algebraic equivalence of 1 as the identity element for multiplication'. In Turn 6 the mathematics educator asks the teacher to give reasons for his answer. Turn 6 and Turn 8 exemplify further evidence of indexical words related to 1 as the identity for multiplication. Turn 8 is, in fact, a repair wherein the teacher modifies, that is, deepens his thinking around the identity for multiplication. In Turn 8 a teacher recognises the ' $\mathrm{KGV}^{\prime}$ ' or LCM from the visually moderated sequences (see Figure 2), based on his site $C$ experiences. The Turn 10 reference to 'variable' deserves attention. In the visually moderated sequences (lines A to F), related to simplifying this algebraic fraction, the $x^{\prime}$ s have 'symbolic value,' meaning there is no need to substitute numerical values for them. In the problem in Figure 2, there is no need to substitute numerical values for the $x^{\prime}$ s. Elsewhere in the mathematics curriculum, 'variables' do take on numerical values. This is ambiguous when it comes to site $C$ teachers.

In Turn 13 and Turn 15 the indexical 'minus' can more objectively be replaced with 'subtract'. Also evident in Turns 13-17 are ways the teacher, following the lexical support system design of the problem set, attempts deepening her mathematical thinking by reasoning on the surface structure of algebra; for example, she refers to terms and common denominator. Turn 18 is a repair in which the mathematics educator modifies the conversation by inserting 'equivalence' as a way to point to the algebraic equivalence of 1 .

Turn 20 and Turn 21 are repairs in which the mathematics educator 'keeps sites in sight' by using equivalent fractions examples to explain algebraic equivalence. Also, in Turn 20 he uses the pervading indexical 'minus' instead of 'subtract'. At this point, as learned from Barnes and Law (1976), it is clear that indexical expressions and words are an essential and irreparable feature of all talk. Turn 21 is an epistemic order in which the teacher makes clear the importance of DMT around 1 as the identity for multiplication, that is, Line B. 


\section{Concluding remarks}

The purpose of this article was to explore site-related issues by focusing on shifting sites, beyond their physical meaning, in the case of CPD. We started by sketching three physical sites or workplaces, namely the university (site A), the school classroom (site B), and a venue off or on campus (site C), each having attendant ways of knowing, talking, and working with respect to mathematics. Site $C$ is significant because it is a place for mutual engagement between mathematics educators and teachers around mathematics. Data excerpts emanating from site $C$ focused on toolkit problem sets tested on an 'always, sometimes, never true' basis in the case of number and operations, visual and nonvisual salience of algebraic transformations involving exponent laws, and semantic or verbal comments on written procedures for finding the LCM when simplifying an algebraic fraction. These design features of the problem sets served as conversational anchors with the participating teachers. In the design of each of these problem sets, there was evidence of site A and site B inputs. Applying the conversation analysis analytic tools of turn transition relevance places, repair,epistemicorder, and indexicality fromethnomethodology enabled us to find evidence of sites based on site-related issues in the selected data excerpts. In these instances, the notion of a site took on a theoretical meaning, independent of a physical site where the conversations occurred. In other words, meetings with the teachers could, in fact, have occurred perfectly neutrally at a university or at a school.

Answers to the research question - 'What are the site-related issues when it comes to analysing toolkits-based conversations peculiar to a CPD initiative between mathematics educators and a group of teachers?' - have implications. At a general and practical level, university-based mathematics educators have to 'keep sites in sight' when designing toolkits. For example, the toolkits need to incorporate policy document cognitive levels and there needs to be a focus on these cognitive levels when interacting with teachers. Policy documents as boundary objects have a stronger link to what happens in classrooms, compared to toolkits that universitybased mathematics educators bring to teachers. This is an important way to narrow the distance between university and school. Simultaneously, when 'doing interaction' (Ten Have, 1990, p. 24), that is, using the designed toolkits with the teachers, mathematics educators have the task of anticipating 'sites moments' and issues peculiar to conversations across two discursive practices, namely university-based mathematics education and school mathematics teaching.

The indexical expressions or words that emerged from the analysis have implications for CPD work. In the two Grade 8 problem sets there were those associated with meanings of the minus sign and the word 'minus' as they appeared in number, operations, transposing and a symmetry view of equations, and the equality sign and equivalence. In the Grade 9 case, there was the analogy between numerical and algebraic equivalences when simplifying the particular kind of algebraic fraction. What should be noted in all these instances is the power of ambiguity and the ambiguity.
For example, 'bring it over' or 'take it over' have a kinaesthetic imagery for the more objective or mathematically correct word 'transpose'.

Finally, to be effective, university-based mathematics educators in all CPD initiatives have the task of keeping sites 'in sight' whenever they interact with teachers. If not, they are bound to 'lose sight' of the realities of teachers and their classrooms. In turn they need to gain insights around being mindful of how the university and the school relate, each with its peculiar ways of talking and working around the same mathematics.

\section{Acknowledgements Competing interests}

We declare that we have no financial or personal relationships that may have inappropriately influenced us in writing this article.

\section{Authors' contributions}

The article arose from an ongoing continuous professional development project in which C.J. is the principal investigator, R.S. a research fellow and F.G. a collaborator. F.G. was responsible for data collection and analysis. F.G. contributed to the design of the toolkits of the project and to the writing process. R.S. also contributed to the writing process.

\section{Funding information}

This research is supported by the National Research Foundation (NRF) of South Africa under grant number 77941. Standard Bank supported the work with Grade 8 and Grade 9 teachers.

\section{Data availability statement}

Data sharing is not applicable to this article as no new data were created or analysed in this study.

\section{Disclaimer}

Any opinions, findings and conclusions or recommendations expressed in this material are those of the authors and do not necessarily reflect the views of the NRF or Standard Bank.

\section{References}

Barnes, B., \& Law, J. (1976). Whatever should be done with indexical expressions? Theory and Society, 3(2), 223-237. https://doi.org/10.1007/bf00161678

Brown, M.W. (2009). The teacher-tool relationship: Theorizing the design and use of curriculum materials. In J.T. Remillard, B.A. Herbel-Eisenmann, \& G.M. Lloyd (Eds.), Mathematics teachers at work: Connecting curriculum materials and classroom instruction (pp. 17-36). New York, NY: Routledge. Retrieved from https://www. taylorfrancis.com/books/e/9781135855635/chapters/10.4324/9780203884645-11

Byers, W. (2007). How mathematicians think: Using ambiguity, contradiction, and paradox to create mathematics. Princeton, NJ: Princeton University Press. Retrieved from https://press.princeton.edu/titles/8386.html

Clark-Wilson, A., \& Hoyles, C. (2019). A research-informed web-based professional development toolkit to support technology-enhanced mathematics teaching
at scale. Educational Studies in Mathematics, 103(3), 343-359. https://doi. org/10.1007/s10649-018-9836-1 
Cobb, P., \& McClain, K. (2010). The collective mediation of a high-stakes accountability program: Communities and networks of practice. Mind, Culture, and Activity, program: Communities and networks of practice. Mind, Culturt

Collopy, R. (2003). Curriculum materials as a professional development tool: How a mathematics textbook affected two teachers' learning. The Elementary School Journal, 103(3), 227-311. https://doi.org/10.1086/499727

Davis, E., \& Krajcik, J. (2005). Designing educative materials to promote teacher learning. Educational Researcher, 34(3), 3-14. https://doi.org/10.3102/0013189X034003003

Davis, R.B. (1984). Learning mathematics: The cognitive science approach to mathematics education. Norwood, NJ: Ablex Publishing Corporation.

Department of Basic Education. (2011). Curriculum and assessment policy statement: Senior Phase mathematics Grades 7-9. Pretoria: DBE.

Garfinkel, H. (1967). Studies in ethnomethodology (2nd ed.). Englewood Cliffs, NJ: Prentice Hall.

Gattegno, C. (1974). The common sense of teaching of mathematics (2nd ed.). New York, NY: Educational Solutions. Retrieved from http://www.educationalsolutions. com/books-books-for-teachers/the-common-sense-of-teaching-mathematics

Harley, K., \& Wedekind, V. (2004). Political change, curriculum change and socia formation, 1990 to 2002. In L. Chisholm (Ed.), Changing class, education and social change in postapartheid South Africa (pp. 195-220). Cape Town: HSRC Press.

Heritage, J. (1984). Garfinkel and ethnomethodology. New York, NY: Polity Press.

Heritage, J. (2009). Conversation analysis as social theory, In B.S. Turner (Ed.), The new Blackwell companion to social theory (pp. 300-320). Oxford: Blackwell. https:/doi. org/10.1002/9781444304992.ch15

Ingram, J. (2018). Moving forward with ethnomethodological approaches to analysing mathematics classroom interactions. ZDM: The International Journal on Mathematics Education, 50(6), 1065-1075. https://doi.org/10.1007/s11858-018-0951-3

Julie, C. (2013). Towards a model for intentional teaching for improving achievement in high-stakes mathematics examinations. In Z. Davis \& S. Jaffer (Eds.), Proceedings of the 19th Annual National Congress of the Association for Mathematics Education of South Africa (Vol. 1, pp. 86-96). Cape Town: AMESA. Retrieved from http://www.amesa.org.za/AMESA2013/Files/P11.pdf

Kieran, C. (1981). Concepts associated with the equality symbol. Educational Studies in Mathematics, 12(3), 317-326. https://doi.org/10.1007/bf00311062

Kieran, C. (1992). The learning and teaching of school algebra. In D.A. Grouws (Ed.), Handbook of research on mathematics teaching and learning (pp. 390-419). New York, NY: MacMillan

Kindt, M. (2011). Principles of practice. In P. Drijvers (Ed.), Secondary algebra education: Revisiting topics and themes and exploring the unknown (pp. 137-178). Rotterdam: Sense Publishers. https://doi.org/10.1007/978-94-6091-334-1_1

Kirshner, D. (1985). Linguistic and mathematical competence. For the Learning of Mathematics, 5(2), 31-33. Retrieved from http://www.jstor.org/stable/40247778

Kirshner, D. (1989). The visual syntax of algebra. Journal for Research in Mathematics Education, 20(3), 274-287. https://doi.org/10.2307/749516

Kirshner, D., \& Awtry, T. (2004). Visual salience of algebraic transformations. Journal for Research in Mathematics Education, 35(4), 224-257. https://doi.org/10.2307/ 30034809

Liebenberg, R., Sasman, M., \& Olivier, A. (1999). From numerical equivalence to algebraic equivalence. Proceedings of the Fifth Annual National Congress of the Association for Mathematics Education of South Africa (Vol. 2, pp. 173-183). Port Elizabeth: AMESA. Retrieved from http://academic.sun.ac.za/mathed/malati/Files/Structure992.pdf

Lortie, D. (1975). Schoolteacher: A sociological study. Chicago, IL: University of Chicago Press.

Lynch, M. (2000). The ethnomethodological foundations of conversation analysis. Text-Interdisciplinary Journal for the Study of Discourse, 20(4), 517-532. https:// doi.org/10.1515/text.1.2000.20.4.517

Matz, M. (1980). Towards a computational theory of algebraic competence. The Journal of Mathematical Behaviour, 3(1), 93-166.
May, B., \& Julie, C. (2014). Deepening thinking-like problems: The case of two students. In M. Lebitso \& A. Maclean (Eds). Proceedings of the 20th Annual National Congress of the Association for Mathematics Education of South Africa (Vol. 1, pp. 103-139). Kimberley: AMESA. Retrieved from http://www.amesa.org. za/AMESA2014/Proceedings/index.html

Maynard, D.W., \& Clayman, S.E. (2003). Ethnomethodology and conversation analysis, In L.T. Reynolds \& N. Herman-Kinney (Eds.), Handbook of symbolic interactionism (pp. 173-202). Walnut Creek, CA: Altamira Press.

National Council of Teachers of Mathematics. (2000). Principles and standards for school mathematics. Reston, VA: NCTM.

Niss, M. (2007). The concept and role of theory in mathematics education. In C. Bergsten, B. Grevholm, H. Masoval, \& F. Ronning (Eds.), Relating practice and theory in mathematics education. Proceedings of NORMA 05 (pp. 97-110). Trondheim: Trondheim University Press.

Okitowamba, O., Julie, C., \& Mbekwa, M. (2018). The effects of examination-driven teaching on mathematics achievement in Grade 10 school-based high-stakes examinations. Pythagoras, 39(1), a377. https://doi.org/10.4102/pythagoras. v39i1.377

Paton, C. (2016, January 20). SA schools under SADTU dominion. Business Day Live. Retrieved from http://sa-monitor.com/sa-schools-sadtu-dominion-bdlive-20january-2016/

Pomerantz, A., \& Fehr, B.J. (2011). Conversation analysis: An approach to the analysis of social interaction. In T.A. Van Dijk (Ed.), Discourse studies: A multidisciplinary introduction (2nd ed., pp. 165-190). Thousand Oaks, CA: Sage.

Psathas, G. (1995). Conversation analysis: The study of talk-in-interaction. Thousand Oaks, CA: Sage.

Rosnick, P. (1981). Some misconceptions concerning the concept of variable. Mathematics Teacher, 74(6), 418-420.

Roth, W.M. (1998). Designing communities. Dordrecht: Kluwer Academic. https://doi. org/10.1007/978-94-011-5562-5

Setati, M. (2005). Researching, teaching and learning in school from 'with' or 'on' teachers to 'with' and 'on' teachers: Conversations. Perspectives in Education, 23(1), 91-101. Retrieved from https://hdl.handle.net/10520/EJC87300

Sfard, A. (2000). Symbolizing mathematical reality into being - Or how mathematical discourse and mathematical objects create each other. In P. Cobb, E. Yackel, \& K. McClain (Eds.), Symbolizing and communicating in mathematics classrooms. Perspectives on discourse, tools, and instructional design (pp. 37-98). Mahwah, $\mathrm{NJ}$ : Lawrence Erlbaum Associates. https://doi.org/10.4324/9781410605351

Smith, C.R. (2015). Continuous professional learning community of mathematics teachers in the Western Cape: Developing a professional learning community through a school-university partnership. Unpublished doctoral dissertation, University of the Western Cape, Bellville, South Africa. Retrieved from http://etd. uwc.ac.za/xmlui/handle/11394/4943

Ten Have, P. (1990). Methodological issues in conversation analysis1. Bulletin of Sociological Methodology/Bulletin de Méthodologie Sociologique, 27(1), 23-51. https://doi.org/10.1177/075910639002700102

Ten Have, P. (1999). Doing conversation analysis: A practical guide. London: Sage. https://doi.org/10.4135/9781849208895

Usiskin, Z. (1988). Conceptions of school algebra and uses of variables. In A. Coxford \& A.P. Schulte (Eds.), Ideas of algebra, K-12 (pp. 8-19). Reston, VA: NCTM

Vlassis, J. (2004). Making sense of the minus sign or becoming flexible in 'negativity'. Learning and Instruction, 14(5), 469-484. https://doi.org/10.1016/j. learninstruc.2004.06.012

Vlassis, J. (2008). The role of mathematical symbols in the development of number conceptualization: The case of the minus sign. Philosophical Psychology, 21(4), 555-570. https://doi.org/10.1080/09515080802285552

Watson, A., \& Mason, J. (1998). Questions and prompts for mathematical thinking. Derby: Association of Teachers of Mathematics. 